\title{
High-throughput decoding of drug targets and drug resistance mechanisms in African trypanosomes
}

\author{
DAVID HORN \\ London School of Hygiene and Tropical Medicine, Keppel Street, London WC1E 7HT, UK
}

(Received 8 Fanuary 2013; revised 15 February 2013; accepted 17 February 2013)

\begin{abstract}
SUMMARY
The availability of genome sequence data has facilitated the development of high-throughput genetic screening approaches in microbial pathogens. In the African trypanosome, Trypanosoma brucei, genome-scale RNA interference screens have proven particularly effective in this regard. These genetic screens allow for identification of the genes that contribute to a particular pathway or mechanisms of interest. The approach has been used to assess loss-of-fitness, revealing the genes and proteins required for parasite viability and growth. The outputs from these screens predict essential and dispensable genes and facilitate drug target prioritization efforts. The approach has also been used to assess resistance to anti-trypanosomal drugs, revealing the genes and proteins that facilitate drug uptake and action. These outputs also highlight likely mechanisms underlying clinically relevant drug resistance. I first review these findings in the context of what we know about current drugs. I then describe potential contributions that these high-throughput approaches could make to the development and implementation of new drugs.
\end{abstract}

Key words: Leishmania, RIT-seq, RNA interference, Trypanosoma brucei, Trypanosoma cruzi.

\section{INTRODUCTION}

The African trypanosomes, Trypanosoma brucei, are protozoan parasites transmitted by tsetse flies in subSaharan Africa. They cause sleeping sickness in humans (Brun et al. 2010) and Nagana in livestock. The other major human pathogenic trypanosomatids are the South American trypanosome, Trypanosoma cruzi and Leishmania spp., which cause Chagas' disease and leishmaniasis, respectively. These are collectively known as the 'Tritryps'. Although the discussion here is focused on approaches to drug design against African trypanosomes, some aspects are certainly relevant to the other Tritryps.

There are two broadly defined starting points in terms of anti-infective drug discovery. The first is to test compounds against live parasites, so-called phenotypic screening. The second is to test compounds against a defined target, so-called targetbased screening. Phenotypic screening does not require any detailed knowledge of the biochemistry and molecular biology of the parasite, and early work in this area began with this approach. In contrast, target-based screening typically requires a recombinant enzyme activity assay. Thus, phenotypic screening reflects the interaction of a compound with the whole parasite, while target-based screening reflects the interaction with a particular target,

Corresponding author: London School of Hygiene and Tropical Medicine, Keppel Street, London WC1E 7HT, UK. Tel: +44207927 2352. Fax: +442076368739. E-mail: david.horn@1shtm.ac.uk typically an enzyme. The former approach is particularly prone to leaving major gaps in our understanding of drug-parasite interaction while the latter is prone to high rates of attrition as assessment progresses, due to low-efficiency drug uptake or drug efflux by parasites, for example. Both approaches are prone to further attrition during in vivo testing. An appreciation of past limitations and new high-throughput approaches has contributed to the emergence of new paradigms in drug design and discovery. In addition to the concepts developed below, the concept of network pharmacology is also worth noting here, whereby drugs may be developed to target multiple proteins simultaneously (Hopkins, 2008).

ORIGIN OF CURRENT AND EMERGING ANTI-TRYPANOSOMAL DRUGS

Anti-trypanosomal drug development has a long history, particularly due to the pioneering work of Paul Ehrlich (Ehrlich, 1913). Indeed, dye-related (suramin) and arsenical compounds (melarsoprol) that emerged then are still in use today, despite the fact that the targets remain unknown. Several drugs used against trypanosomatids, such as the diamidines, used in humans (pentamidine) and livestock (berenil), and isometamidium and ethidium bromide, used in livestock, are thought to target DNA (Wilson et al. 2008). Because activity depends upon DNA binding, these drugs would not be identified for follow-up from a conventional 
target-based screen. On the other hand, they might be expected to display toxicity through disruption of host DNA metabolism. These drugs do display a good degree of selective action in some cases, however. This is because the DNA that appears to be most susceptible to drug-induced damage, the kinetoplast DNA or mitochondrial genome, displays parasite-specific features that likely render this genome particularly susceptible to these drugs (Shapiro and Englund, 1990; Roy Chowdhury et al. 2010). Selective accumulation is also important here. Not only may some drugs be concentrated by trypanosome transporters, they may be selectively accumulated in the trypanosome mitochondrion, effectively delivering the drug to its target site. Regardless of the target(s), where efficacy is dependent upon accumulation and concentration by the parasite, potential drugs will typically only be identified in phenotypic screens and not in target-based screens.

More recently, regulatory requirements, and the drive to develop a better understanding of drug efficacy and toxicity, have played a part in promoting the more costly, specific target-based approaches. Despite this, eflornithine was the first, and only current, anti-trypanosomal drug to emerge from a target-based approach. This drug is an aminoacid analogue and irreversible inhibitor of ornithine decarboxylase (Bacchi et al. 1980). Initially developed as anti-cancer chemotherapy, this drug was repurposed as an anti-trypanosomal. The advantages of target-based screening are that the mechanisms of drug action are understood and that rational approaches can be applied to the medicinal chemistry component of drug development; potency against the parasite target may be increased and off-target effects against the host may be reduced (see Frearson et al. 2010 for example). Thus, in general, phenotypic screening identifies drugs with unknown, possibly multiple, targets and provides no prior information that can guide medicinal chemistry. It should be borne in mind, however, that even a 'specific' inhibitor of a particular enzyme may also interfere with other targets, and these 'off-target' effects will usually remain mysterious since development and optimization are typically carried out using the single target enzyme. There are limitations, therefore, to understanding possible 'off-target' effects in the parasite and in the host, regardless of the starting point.

Eflornithine is now typically administered in combination with the nitrofuran, nifurtimox (Priotto et al. 2009), a pro-drug that was initially used against T. cruzi. There are also 2 new drugs currently progressing through clinical trials against sleeping sickness; another nitro pro-drug, the nitroimidazole, fexinidazole (Kaiser et al. 2011) and a boron-based benzoxaborole, SCYX-7158 (Jacobs et al. 2011). The nitro pro-drugs are known to be activated by a nitroreductase (Hall et al. 2011; Wyllie et al. 2012) but the targets of the nitro-drugs and the benzoxaboroles remain unknown.

It is notable that all but one of the drugs used in the past or currently in clinical trials against African trypanosomes have emerged from a phenotypic screening approach. To date, none of these drugs has a known target, illustrating the difficulty in identifying targets after phenotypic screening. The current drugs are 'effective', in the sense that they have saved many lives, but there are problems associated with their use. The arsenic-based drug, melarsoprol, for example, displays high levels of toxicity, resulting in a reactive encephalopathy in up to $5 \%$ of patients treated (Pepin and Milord, 1994). Even the drug with a known target, eflornithine, has a surprisingly low potency against trypanosomes; it displays a $50 \%$ effective growth-inhibitory concentration $\left(\mathrm{EC}_{50}\right)$ of approximately $20 \mu \mathrm{M}$. Screening programmes do not follow up compounds with such low potency and typically aim to achieve a submicromolar $\mathrm{EC}_{50}$ following further development through medicinal chemistry. As a consequence, a single eflornithine treatment requires more than $200 \mathrm{~g}$ of drug and many litres of saline administered over a 10-day period. It seems unlikely that any drug with either of the features described above, up to $5 \%$ lethality or $\mathrm{EC}_{50}$ of $20 \mu \mathrm{M}$, would progress through the development, trial and approval process today. This situation certainly reflects the economics of drug development and also raises the issue of whether current processes are too stringent for the 'neglected tropical diseases'. Thus, there are clearly problems associated with current anti-trypanosomal drugs.

The goal is to develop cheap, orally administered, potent, yet safe drugs; these will ideally be applied as combination therapies to minimize the emergence and spread of drug resistance. The question considered below is whether findings that emerge from high-throughput RNA interference (RNAi) screens can identify better targets as starting points for target-based screening, fill some of the knowledge gaps left following phenotypic screening and, more generally, improve our understanding of drugparasite interactions.

HIGH - THROUGHPUT GENETIC SCREENS IN AFRICAN TRYPANOSOMES

\section{Genome-scale RNA interference in}

Trypanosoma brucei

The availability of genome sequence data has facilitated the development of high-throughput genetic screening approaches for a number of microbial pathogens. Reference genome sequences were reported for each of the Tritryps in 2005 (Berriman et al. 2005; El-Sayed et al. 2005; Ivens et al. 2005). The range of molecular genetic tools available for studies in T. brucei, and particularly the 
A

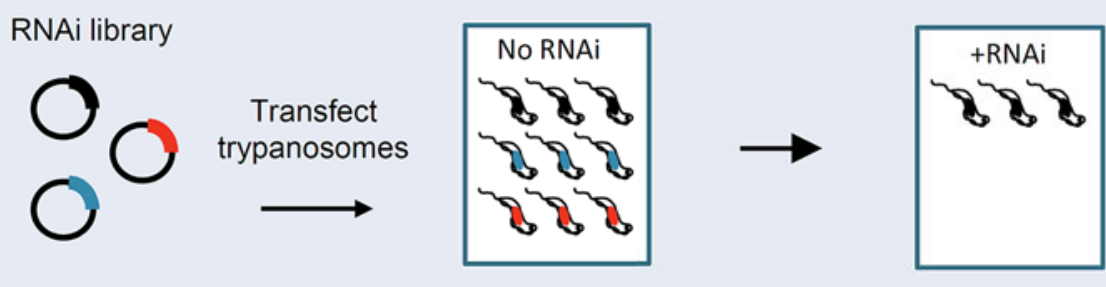

B

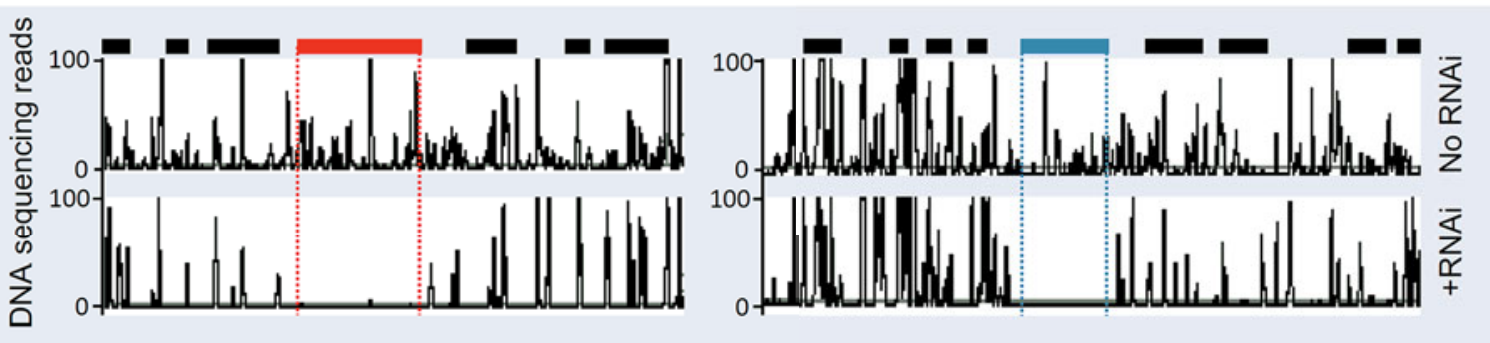

Fig. 1. Genome-scale RNAi library screens identify the genes required for parasite growth - the 'survivasome' (see Alsford et al. 2011). (A) The schematic shows distinct RNAi constructs used to generate a highly complex collection of pooled clones - the library. Once RNAi is induced (using tetracycline) cells with dispensable proteins knocked down will continue to grow while cells with essential proteins knocked down will be lost from the pool. Deep sequencing of the RNAi constructs represented in the pool can be used to reflect relative representation. (B) Examples of RIT-seq outputs; sequences were mapped to the Trypanosoma brucei reference genome. Cold-spots coincide with putative essential genes (red and blue).

RNAi machinery in this trypanosomatid (Ngo et al. 1998), have greatly facilitated the development of high-throughput genetic screens. RNAi operates in response to double-stranded RNA (dsRNA) and this can be exploited experimentally for sequencespecific knockdown of individual gene transcripts. The behaviour and characteristics of knockdown cells reveal the function of the targeted gene and protein. Genome-scale RNAi screens have proven to be particularly effective in T. brucei (Morris et al. 2002; Baker et al. 2011; Schumann Burkard et al. 2011). When coupled to deep sequencing, RNA Interference Target sequencing, or RIT-seq, allows for the generation of genome-scale datasets, indicating the cohort of genes linked to a particular function, pathway or mechanism of interest (Alsford et al. 2011, 2012).

\section{Genome-scale identification of essential genes in Trypanosoma brucei}

RIT-seq was initially used to identify the genes and proteins that are required for parasite viability and growth (Alsford et al. 2011). A library comprising a highly complex collection of clones, each with a different gene knocked down depending on the dsRNA expressed, was monitored for growth defects (Fig. 1A). This was achieved by using deepsequencing to survey the representation of each clonal population in the pool. When sequences were mapped to the reference genome, populations that had been lost from the pool were identified as coldspots where sequence-reads diminished over time (Fig. 1B). Statistical analysis of the outputs revealed over 1000 putative essential genes among approximately 7500 annotated in the genome. These 'survivasome' outputs can be used to predict both essential and dispensable genes and to facilitate drug target prioritization efforts. For this purpose, the dataset has been incorporated into the TDR Targets database, a chemogenomics database for neglected diseases (Magarinos et al. 2012). It should be possible to refine the list of essential genes to a more definitive 'infectome' by running similar screens in an in vivo model.

Genome-scale identification of genes associated with drug resistance in Trypanosoma brucei

RIT-seq was also used for genome-scale RNAi library screening in the presence of anti-trypanosomal drugs (Alsford et al. 2012). In this case, genetically unperturbed populations were killed by a drug and only those cells that lost functions required for drug efficacy survived (Fig. 2A). These populations were identified as hot-spots where sequence-reads increased over time (Fig. 2B). Analysis of these outputs revealed all 3 known genes (Maser et al. 1999; Wilkinson et al. 2008; Vincent et al. 2010) and more than 50 new genes linked to drug efficacy. These 
A

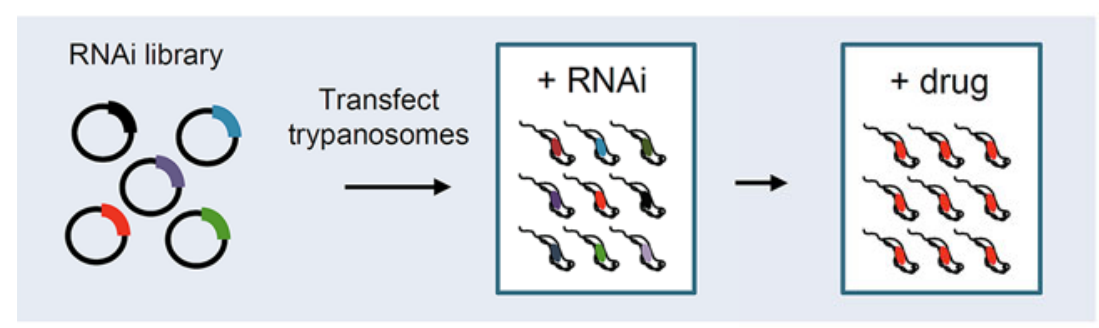

B

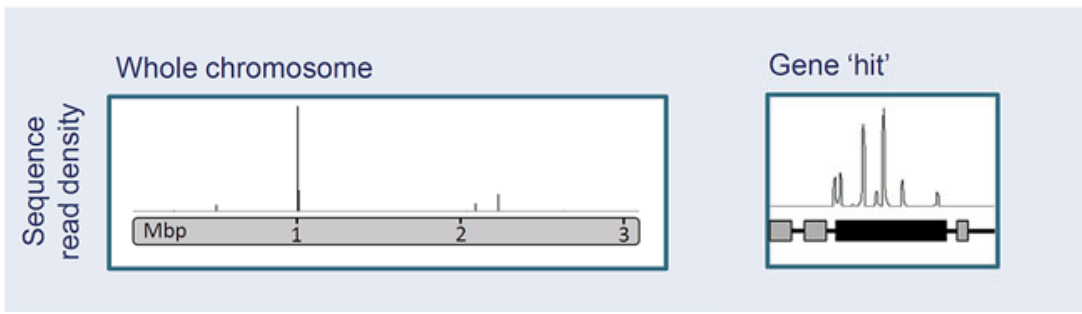

Fig. 2. Genome-scale RNAi library screens identify the genes required for drug action and potentially involved in drug resistance (see Alsford et al. 2012). (A) The schematic shows distinct RNAi constructs used to generate a highly complex collection of pooled clones - the library. Only cells with proteins that facilitate drug action knocked down will continue to grow under antitrypanosomal drug selection while other cells will be lost from the pool. Deep sequencing of the RNAi constructs represented in the pool can be used to reflect relative representation. (B) Examples of RIT-seq outputs; sequences were mapped to the Trypanosoma brucei reference genome. Hot-spots coincide with genes involved in drug uptake and action, the chromosome map shows 4 'hits'. A close-up view of a single hit reveals a signature representing multiple RNAi target fragments.

outputs reveal the genes and proteins that facilitate drug action and also highlight likely mechanisms underlying clinically relevant drug resistance. Transporter mechanisms involved in the uptake of eflornithine, pentamidine, melarsoprol and suramin were identified while, in the case of nifurtimox, the enzymatic pro-drug activator was identified. Suramin delivery to the lysosome was found to be via receptor (invariant surface glycoprotein 75)mediated endocytosis (Alsford et al. 2012). In a follow-up study, a specific aquaglyceroporin was linked to the long-sought mechanism of melarsoprolpentamidine uptake and cross-resistance (Baker et al. 2012).

POTENTIAL CONTRIBUTIONS TO THE DEVELOPMENT OF NEW DRUGS

High-throughput genetic approaches, allied with other approaches, such as metabolomics, should continue to provide an even more detailed picture of drug action and potential resistance in trypanosomes. Anti-trypanosomal drugs developed for use against T. brucei, T. cruzi or Leishmania spp. could be screened against $T$. brucei RNAi libraries. A better understanding of drug-parasite interaction could facilitate the repurposing of some of these compounds among diseases caused by these parasites. One outcome may be that those drugs thought to target DNA actually kill cells through alternative and unanticipated mechanisms. There is also the possibility that the new insights will retrospectively facilitate the rational medicinal chemistry-based optimization of drugs initially identified through phenotypic screening. Some specific examples of new opportunities emerging from genome-scale RNAi library screens are detailed below.

Current RIT-seq datasets can already be used for drug-target prioritization efforts (Alsford et al. 2011; Magarinos et al. 2012). Pathways that are required specifically to survive the hostile host environment in terms of coping with immune pressure or nutrient limitations, when characterized in the future, may represent excellent examples of an 'Achilles' heel' for the parasite. Other RIT-seq screens will allow for high-throughput decoding of a variety of virulence mechanisms in T. brucei. The impact of host toxins such as trypanosome lytic factors (Vanhollebeke and Pays, 2010) could be enhanced by therapies that inhibit parasite defences. The host immune system could be harnessed by therapies that disrupt the mechanism underlying antigenic variation and variant surface glycoprotein allelic exclusion (Horn and McCulloch, 2010). The life-cycle differentiation process (MacGregor et al. 2012) could be artificially triggered to block parasite division. The approach should also be adaptable to other microbial pathogens.

Identification of the mutations most likely to be associated with clinical cases of current drugresistance could be exploited to develop diagnostic tests for those mutations. Alternatively, a fluorescent 
drug analogue could be used as a biomarker to monitor uptake (Stewart et al. 2005). Such tools could be used for surveillance and this could impact policy in terms of selecting the region in greatest need of a new therapy. RNAi screens using compounds currently progressing through clinical trials could yield insights into the mode of uptake and action before these drugs are approved and widely used. Uptake via an essential transporter pathway would be good news in terms of indicating reduced probability of the development of resistance. In contrast, uptake via a dispensable pathway would predict emergence of resistance to a monotherapy. The drug in question in the latter case may be better used as part of a combination, with a second drug known to be taken up by a different route. Endocytosis and drug transporters, once known, could also be exploited to deliver new toxic cargoes.

Thus, it will be of practical use to know more about how drugs are taken up, which proteins and metabolites they interact with once taken up and how they ultimately kill trypanosomes. In this context, outputs from high-throughput genetic screens could present a range of new opportunities. As we learn more about in vivo virulence mechanisms, appropriate targets within readily exploitable pathways will emerge. In the case of drugs identified in phenotypic screens, subsequent target deconvolution may become readily achievable, making this approach even more attractive as a starting point. Understanding the range of drug-uptake mechanisms specific to trypanosomes could facilitate the delivery of toxins, including toxins with known targets. Once the genetic basis is known, it will be possible to monitor the emergence and spread of resistance and a more rational approach could also be taken to reducing the probability of resistance to new drugs.

\section{CONCLUSIONS AND FUTURE DIRECTIONS}

It should be possible to exploit genome-scale genetic screens to learn more about old and new drugs, to identify new targets and to develop improved drugs. Target-based approaches have dominated drugdiscovery efforts for some time. This has been largely driven by the need to take rational approaches to increasing potency and reducing toxicity. However, these efforts are associated with high attrition rates, meaning that the cost of producing a single effective drug has increased dramatically. This situation is unrealistic for many diseases and possibly even more so for the neglected tropical diseases such as sleeping sickness. As a result, phenotype screening against parasites has seen a resurgence in popularity in recent years, but this leaves a gap in our understanding of the mechanism of drug action. As a consequence, when the mode of action is a mystery, little can be done to tackle any cases of toxicity or drug resistance.
In conclusion, genomics has not yet had a major impact on anti-trypanosomal therapy but it shows great promise of doing so in the future. High-throughput genetic screens should facilitate drug-target prioritization for target-based approaches and will also illuminate available drug-delivery routes in terms of transporters and receptor-mediated endocytosis. A deeper understanding of parasite biology, including knowledge regarding parasite-drug interactions, should ultimately facilitate a more rational approach to maximizing anti-trypanosomal drug efficacy as well as minimizing host toxicity and potential resistance.

\section{F INANCIAL S UPPORT}

I gratefully acknowledge funding from the Wellcome Trust (Project grant 093010).

\section{REFERENCES}

Alsford, S., Turner, D. J., Obado, S. O., Sanchez-Flores, A., Glover, L., Berriman, M., Hertz-Fowler, C. and Horn, D. (2011). High-throughput phenotyping using parallel sequencing of RNA interference targets in the African trypanosome. Genome Research 21, 915-924.

Alsford, S., Eckert, S., Baker, N., Glover, L., Sanchez-Flores, A., Leung, K. F., Turner, D. J., Field, M. C., Berriman, M. and Horn, D. (2012). High-throughput decoding of antitrypanosomal drug efficacy and resistance. Nature 482, 232-236. doi: 10.1038/nature10771.

Bacchi, C. J., Nathan, H.C., Hutner, S. H., Mccann, P.P. and Sjoerdsma, A. (1980). Polyamine metabolism: a potential therapeutic target in trypanosomes. Science 210, 332-334.

Baker, N., Alsford, S. and Horn, D. (2011). Genome-wide RNAi screens in African trypanosomes identify the nifurtimox activator NTR and the eflornithine transporter AAT6. Molecular and Biochemical Parasitology 176, $55-57$.

Baker, N., Glover, L., Munday, J. C., Aguinaga Andres, D., Barrett, M.P., De Koning, H.P. and Horn, D. (2012). Aquaglyceroporin 2 controls susceptibility to melarsoprol and pentamidine in African trypanosomes. Proceedings of the National Academy of Sciences, USA 109, 10996-11001. doi: 1202885109 [pii] 10.1073/pnas.1202885109 Berriman, M., Ghedin, E., Hertz-Fowler, C., Blandin, G., Renauld, H., Bartholomeu, D. C., Lennard, N. J., Caler, E., Hamlin, N.E., Haas, B., Bohme, U., Hannick, L., Aslett, M. A., Shallom, J., Marcello, L., Hou, L., Wickstead, B., Alsmark, U.C., Arrowsmith, C., Atkin, R. J., Barron, A. J., Bringaud, F., Brooks, K., Carrington, M., Cherevach, I., Chillingworth, T. J., Churcher, C., Clark, L. N., Corton, C. H., Cronin, A., Davies, R. M., Doggett, J., Djikeng, A., Feldblyum, T., Field, M. C., Fraser, A., Goodhead, I., Hance, Z., Harper, D., Harris, B. R., Hauser, H., Hostetler, J., Ivens, A., Jagels, K., Johnson, D., Johnson, J., Jones, K., Kerhornou, A.X., Koo, H., Larke, N., Landfear, S., Larkin, C., Leech, V., Line, A., Lord, A., Macleod, A., Mooney, P. J., Moule, S., Martin, D. M., Morgan, G.W., Mungall, K., Norbertczak, H., Ormond, D., Pai, G., Peacock, C.S., Peterson, J., Quail, M. A., Rabbinowitsch, E., Rajandream, M. A., Reitter, C., Salzberg, S. L., Sanders, M., Schobel, S., Sharp, S., Simmonds, M., Simpson, A. J., Tallon, L., Turner, C. M., Tait, A., Tivey, A. R., Van Aken, S., Walker, D., Wanless, D., Wang, S., White, B., White, O., Whitehead, S., Woodward, J., Wortman, J., Adams, M.D., Embley, T.M., Gull, K., Ullu, E., Barry, J.D., Fairlamb, A. H., Opperdoes, F., Barrell, B. G., Donelson, J. E., Hall, N., Fraser, C. M., Melville, S. E. and El-Sayed, N. M. (2005). The genome of the African trypanosome Trypanosoma brucei. Science 309, 416-422.

Brun, R., Blum, J., Chappuis, F. and Burri, C. (2010). Human African trypanosomiasis. Lancet 375, 148-159.

Ehrlich, P. (1913). Address in pathology, on chemotherapy: delivered before the Seventeenth International Congress of Medicine. British Medical fournal 2, 353-359.

El-Sayed, N. M., Myler, P. J., Bartholomeu, D. C., Nilsson, D., Aggarwal, G., Tran, A. N., Ghedin, E., Worthey, E. A., 
Delcher, A. L., Blandin, G., Westenberger, S. J., Caler, E., Cerqueira, G. C., Branche, C., Haas, B., Anupama, A., Arner, E., Aslund, L., Attipoe, P., Bontempi, E., Bringaud, F., Burton, P., Cadag, E., Campbell, D. A., Carrington, M., Crabtree, J., Darban, H., Da Silveira, J. F., De Jong, P., Edwards, K. Englund, P. T., Fazelina, G., Feldblyum, T., Ferella, M. Frasch, A. C., Gull, K., Horn, D., Hou, L., Huang, Y., Kindlund, E., Klingbeil, M., Kluge, S., Koo, H., Lacerda, D., Levin, M. J., Lorenzi, H., Louie, T., Machado, C. R., Mcculloch, R., Mckenna, A., Mizuno, Y., Mottram, J. C., Nelson, S., Ochaya, S., Osoegawa, K., Pai, G., Parsons, M., Pentony, M., Pettersson, U., Pop, M., Ramirez, J. L., Rinta, J., Robertson, L., Salzberg, S. L., Sanchez, D. O., Seyler, A., Sharma, R., Shetty, J., Simpson, A. J., Sisk, E., Tammi, M.T., Tarleton, R., Teixeira, S., Van Aken, S., Vogt, C., Ward, P. N., Wickstead, B., Wortman, J., White, O., Fraser, C. M., Stuart, K. D. and Andersson, B. (2005). The genome sequence of Trypanosoma cruzi, etiologic agent of Chagas disease. Science 309, 409-415. doi: 10.1126/science.1112631.

Frearson, J. A., Brand, S., Mcelroy, S. P., Cleghorn, L. A., Smid, O., Stojanovski, L., Price, H.P., Guther, M. L., Torrie, L. S., Robinson, D. A., Hallyburton, I., Mpamhanga, C.P. Brannigan, J. A., Wilkinson, A. J., Hodgkinson, M., Hui, R., Qiu, W., Raimi, O. G., Van Aalten, D. M., Brenk, R., Gilbert, I. H., Read, K. D., Fairlamb, A. H., Ferguson, M. A., Smith, D. F. and Wyatt, P. G. (2010). $N$-myristoyltransferase inhibitors as new leads to treat sleeping sickness. Nature 464, 728-732. doi: nature08893 [pii] 10.1038/nature08893. Hall, B. S., Bot, C. and Wilkinson, S. R. (2011). Nifurtimox activation by trypanosomal type I nitroreductases generates cytotoxic nitrile metabolites. Fournal of Biological Chemistry 286, 13088-13095. doi: M111.230847 [pii] 10.1074/jbc.M111.230847.

Hopkins, A. L. (2008). Network pharmacology: the next paradigm in drug discovery. Nature Chemical Biology 4, 682-690. doi: nchembio.118 [pii] 10.1038/nchembio.118.

Horn, D. and McCulloch, R. (2010). Molecular mechanisms underlying the control of antigenic variation in African trypanosomes. Current Opinion in Microbiology 13, 700-705. doi: S1369-5274(10)00123-2 [pii] 10.1016/j. mib.2010.08.009.

Ivens, A. C., Peacock, C. S., Worthey, E. A., Murphy, L., Aggarwal, G., Berriman, M., Sisk, E., Rajandream, M. A., Adlem, E., Aert, R., Anupama, A., Apostolou, Z., Attipoe, P., Bason, N., Bauser, C. Beck, A., Beverley, S. M., Bianchettin, G., Borzym, K., Bothe, G., Bruschi, C. V., Collins, M., Cadag, E., Ciarloni, L., Clayton, C., Coulson, R. M., Cronin, A., Cruz, A.K., Davies, R.M., De Gaudenzi, J., Dobson, D.E., Duesterhoeft, A., Fazelina, G. Fosker, N., Frasch, A.C., Fraser, A., Fuchs, M., Gabe1, C., Goble, A., Goffeau, A., Harris, D., Hertz-Fowler, C., Hilbert, H., Horn, D., Huang, Y., Klages, S., Knights, A., Kube, M., Larke, N., Litvin, L., Lord, A., Louie, T., Marra, M., Masuy, D., Matthews, K. Michaeli, S., Mottram, J.C., Muller-Auer, S., Munden, H., Nelson, S., Norbertczak, H., Oliver, K., O’Neil, S., Pentony, M., Pohl, T. M., Price, C., Purnelle, B., Quail, M. A., Rabbinowitsch, E., Reinhardt, R., Rieger, M., Rinta, J., Robben, J., Robertson, L., Ruiz, J. C., Rutter, S., Saunders, D., Schafer, M., Schein, J., Schwartz, D. C., Seeger, K., Seyler, A., Sharp, S., Shin, H., Sivam, D., Squares, R., Squares, S., Tosato, V., Vogt, C., Volckaert, G., Wambutt, R., Warren, T., Wedler, H., Woodward, J., Zhou, S., Zimmermann, W., Smith, D. F., Blackwell, J. M., Stuart, K. D., Barrell, B. and Myler, P. J. (2005). The genome of the kinetoplastid parasite, Leishmania major. Science 309, 436-442. doi: $10.1126 /$ science. 1112680

Jacobs, R. T., Nare, B., Wring, S. A., Orr, M. D., Chen, D., Sligar, J. M., Jenks, M. X., Noe, R. A., Bowling, T. S., Mercer, L. T., Rewerts, C., Gaukel, E., Owens, J., Parham, R., Randolph, R., Beaudet, B. Bacchi, C. J., Yarlett, N., Plattner, J. J., Freund, Y., Ding, C., Akama, T., Zhang, Y. K., Brun, R., Kaiser, M., Scandale, I. and Don, R. (2011). SCYX-7158, an orally-active benzoxaborole for the treatment of stage 2 human African trypanosomiasis. PLoS Neglected Tropical Diseases 5, e1151. doi: 10.1371/journal.pntd.0001151 PNTD-D10-00094 [pii].
Kaiser, M., Bray, M. A., Cal, M., Bourdin Trunz, B., Torreele, E. and Brun, R. (2011). Antitrypanosomal activity of fexinidazole, a new oral nitroimidazole drug candidate for treatment of sleeping sickness. Antimicrobial Agents and Chemotherapy 55, 5602-5608. doi: AAC.0024611 [pii] 10.1128/AAC.00246-11.

MacGregor, P., Szoor, B., Savill, N. J. and Matthews, K. R. (2012). Trypanosomal immune evasion, chronicity and transmission: an elegant balancing act. Nature Reviews Microbiology 10, 431-438. doi: nrmicro2779 [pii] 10.1038/nrmicro2779.

Magarinos, M.P., Carmona, S. J., Crowther, G. J., Ralph, S. A., Roos, D. S., Shanmugam, D., Van Voorhis, W. C. and Aguero, F. (2012). TDR targets: a chemogenomics resource for neglected diseases. Nucleic Acids Research 40, D1118-D1127. doi: gkr1053 [pii] 10.1093/nar/ gkr1053.

Maser, P., Sutterlin, C., Kralli, A. and Kaminsky, R. (1999) A nucleoside transporter from Trypanosoma brucei involved in drug resistance. Science 285, 242-244.

Morris, J. C., Wang, Z., Drew, M.E. and Englund, P. T. (2002). Glycolysis modulates trypanosome glycoprotein expression as revealed by an RNAi library. EMBO fournal 21, 4429-4438.

Ngo, H., Tschudi, C., Gull, K. and Ullu, E. (1998). Double-stranded RNA induces mRNA degradation in Trypanosoma brucei. Proceedings of the National Academy of Sciences, USA 95, 14687-14692.

Pepin, J. and Milord, F. (1994). The treatment of human African trypanosomiasis. Advances in Parasitology 33, 1-47.

Priotto, G., Kasparian, S., Mutombo, W., Ngouama, D. Ghorashian, S., Arnold, U., Ghabri, S., Baudin, E., Buard, V., Kazadi-Kyanza, S., Ilunga, M., Mutangala, W., Pohlig, G., Schmid, C., Karunakara, U., Torreele, E. and Kande, V. (2009). Nifurtimox-eflornithine combination therapy for second-stage African Trypanosoma brucei gambiense trypanosomiasis: a multicentre, randomised, phase III, non-inferiority trial. Lancet 374, 56-64. doi: S0140-6736(09) 61117-X [pii] 10.1016/S0140-6736(09)61117-X.

Roy Chowdhury, A., Bakshi, R., Wang, J., Yildirir, G., Liu, B., Pappas-Brown, V., Tolun, G., Griffith, J. D., Shapiro, T. A., Jensen, R. E. and Englund, P. T. (2010). The killing of African trypanosomes by ethidium bromide. PLoS Pathogenesis 6, e1001226. doi 10.1371/journal.ppat.1001226.

Schumann Burkard, G., Jutzi, P. and Roditi, I. (2011). Genome-wide RNAi screens in bloodstream form trypanosomes identify drug transporters. Molecular and Biochemical Parasitology 175, 91-94.

Shapiro, T. A. and Englund, P. T. (1990). Selective cleavage of kinetoplast DNA minicircles promoted by antitrypanosomal drugs. Proceedings of the National Academy of Sciences, USA 87, 950-954.

Stewart, M. L., Krishna, S., Burchmore, R. J., Brun, R. De Koning, H.P., Boykin, D. W., Tidwell, R. R., Hall, J. E. and Barrett, M. P. (2005). Detection of arsenical drug resistance in Trypanosoma brucei with a simple fluorescence test. Lancet 366, 486-487. doi: S0140-6736(05)66793-1 [pii] 10.1016/S0140-6736(05)66793-1.

Vanhollebeke, B. and Pays, E. (2010). The trypanolytic factor of human serum: many ways to enter the parasite, a single way to kill. Molecular Microbiology 76, 806-814. doi: MMI7156 [pii] 10.1111/j.13652958.2010.07156.x.

Vincent, I. M., Creek, D., Watson, D. G., Kamleh, M. A., Woods, D. J., Wong, P. E., Burchmore, R. J. and Barrett, M. P. (2010). A molecular mechanism for eflornithine resistance in African trypanosomes. PLoS Pathogenesis 6, e1001204.

Wilkinson, S. R., Taylor, M. C., Horn, D., Kelly, J.M. and Cheeseman, I. (2008). A mechanism for cross-resistance to nifurtimox and benznidazole in trypanosomes. Proceedings of the National Academy of Sciences, USA 105, 5022-5027.

Wilson, W. D., Tanious, F. A., Mathis, A., Tevis, D., Hall, J. E. and Boykin, D. W. (2008). Antiparasitic compounds that target DNA. Biochimie 90, 999-1014. doi: S0300-9084(08)00051-5 [pii] 10.1016/j. biochi.2008.02.017.

Wyllie, S., Patterson, S. and Fairlamb, A. H. (2012). Assessing the essentiality of Leishmania donovani nitroreductase and its role in nitro-drug activation. Antimicrobial Agents and Chemotherapy doi: AAC.01788-12 [pii] 10.1128/AAC.01788-12. 